\title{
Parecer sobre o Ensino de Filosofia E de Sociologia ${ }^{1}$
}

\author{
Amaury César Moraes $^{2}$
}

\section{PARECER}

0 presente parecer visa refletir sobre as DCNEM (Parecer CEN/CEB15/98 e Resolução CEN/CEB 03/98), esclarecer alguns de seus pontos que julgamos se encontram em contradição com a LDB, e propor uma interpretação conforme a LDB, em especial em seu artigo $36, \S 1^{\circ}$., inciso III, e com isso alterar o disposto na Resolução CEN/ CEB 03/98, artigo 10, $\S 2^{\circ}$., alínea b).

Para efeito de instrução do presente parecer, dividimo-lo em duas partes, contexto legal e contexto pedagógico e indicamos a seguir as partes referidas:

\section{Parte I - Do Contexto Legal}

LDBEN 9394/96, artigo 36:

$\S 1^{\circ}$. Os conteúdos, as metodologias e as formas de avaliação serão organizadas de tal forma que ao final do ensino médio o educando demonstre:

III - domínio dos conhecimentos de Filosofia e Sociologia necessários ao exercício da cidadania.

\section{DCNEM - PARECER CNE/CEB 15/98:}

(item 5.2) "Nesta área (Ciências Humanas) incluir-se-ão também os estudos de Filosofia e Sociologia necessários ao exercício da cidadania para cumprimento do que manda a letra da lei. (grifos da autora) No entanto, é indispensável lembrar que o

\footnotetext{
${ }^{1}$ Em 2004, o Professor Dr. Amaury César Moraes integrou a equipe do MEC que deveria rever os Parâmetros Curriculares Nacionais de Sociologia (1999). Aprimeira versão do texto que analisava os PCNs (1999), indicava que o maior problema para a disciplina-sociologia era a compreensão das Diretrizes Curriculares Nacionais - DCN - Ensino Médio sobre a transversalidade dos conteúdos de Filosofia e de Sociologia. Segundo a equipe, liderada pelo Amaury César Moraes, antes da revisão dos Parâmetros seria necessária a revisão das Diretrizes. A coordenação do Ensino Médio do MEC aceitou a sugestão e pediu um "parecer" sobre as DCN-EM. Amaury Cesar Moraes elaborou e esse Parecer tornouse a principal peça nos debates da Câmara de Educação Básica do Conselho Nacional de Educação - CNE, em 2006, ajudando a alterar as DCN-EM, tornando obrigatórias as disciplinas de Filosofia e de Sociologia.

${ }^{2}$ Professor Doutor do Departamento de Metodologia do Ensino e Educação comparada na Faculdade de Educação da Universidade de São Paulo - FE-USP.
} 
espírito da LDB é muito mais generoso com a constituição da cidadania e não a confina a nenhuma disciplina específica, como poderia dar a entender uma interpretação literal da recomendação do inciso III do Parágrafo primeiro do artigo 36. Nesse sentido, todos os conteúdos curriculares desta área, embora não exclusivamente dela, deverão contribuir para a constituição da identidade dos alunos e para o desenvolvimento de um protagonismo social solidário, responsável e pautado na igualdade política." (sic)

\section{Resolução CEN/CEB 03/98, ARTigo 10,}

$\S 2^{\circ}$. As propostas pedagógicas das escolas deverão assegurar tratamento interdisciplinar e contextualizado para:

b) Conhecimentos de Filosofia e Sociologia necessários ao exercício da cidadania.

A questão inicial é perguntar se porque não podemos fazer uma "interpretação literal" do dispositivo legal, poderíamos dar-lhe uma "interpretação liberal" como foi feito? Atentando que essa interpretação alterou - não manteve - o espírito da lei. Mas essa controvérsia já vinha anunciada no Parecer CEN/CEB 05/97, denominado "Proposta de Regulamentação da Lei 9394/96", nas seguintes palavras:

Muito provavelmente se pode antecipar a dúvida que será levantada nos sistemas de ensino e nas instituições que os integram, quanto à forma a ser adotada, visando ao "domínio dos conhecimentos de Filosofia e Sociologia" (item 3.4. sobre o Ensino Médio, comentário aos artigos 35 e 36 da LDB 9394/96).

Aqui já se vislumbrava a "dúvida" que as DCNEM resolvem sem muita reflexão ou argumento, apenas atribuindo à lei uma "generosidade" que não restringia à Filosofia e Sociologia a responsabilidade para a constituição da cidadania.

Se atentarmos bem, vemos que entre a lei original (LDB) e a derivada (DCNEM/ Parecer e Resolução) há até mudanças dos termos, como por exemplo, o uso na LDB da palavra "conhecimentos" e no Parecer, "estudos". De certo modo, essa leitura da LDB pela parecerista já induz a uma redução do status do que é requerido pela lei "conhecimentos" para "estudos". Parece-nos que "conhecimentos", em que pese a vagueza ou amplidão do sentido, ou por isso mesmo, tem um status curricular mais elevado do que "estudos" que relativiza bastante a importância e a operacionalização.

Há que se comentar aqui também que tanto na LDB quanto nessa Proposta de Regulamentação (Parecer 05/97) que esses "conhecimentos de Filosofia e Sociologia" integram a base nacional comum e não a parte diversificada, como muita vez as DCNEM acabaram induzindo, levando à compreensão de que a inclusão desses "conhecimentos" como "disciplinas" da parte diversificada era prerrogativa das unidades escolares como exercício de sua autonomia. 
Cabe ainda levar em conta, refletindo e interpretando alguns pareceres que respondiam a consultas sobre a obrigatoriedade ou não de inclusão dessas disciplinas, em especial o Parecer CEN/CEB 22/2003, nomeado "Questionamento sobre currículos da educação básica, das escolas públicas e particulares”. Tal parecer responde desautorizando as Assembléias Legislativas de legislarem sobre currículo escolar, entendendo que essa prerrogativa é exclusiva dos "sistemas de ensino federal, estaduais e municipais", ou seja, o MEC, as Secretarias Estaduais e Municipais de Educação, e os Conselhos Nacional, Estaduais e Municipais de Educação. Mas ao avançar sobre se esses conhecimentos devem ou não ser tratados como "disciplinas" e "obrigatórias", o Parecer, recorrendo à LDB e à Resolução 03/98, pondera que "não há, dentro da legislação pertinente, obrigatoriedade de oferecer Filosofia e Sociologia como disciplinas". Ora, na lei original não há mesmo explicitamente a definição de Sociologia e Filosofia como "disciplinas" e "obrigatórias". A legislação derivada, que se põe aqui em questão, dá um sentido já definido para esses conhecimentos - "tratamento interdisciplinar e contextualizado" -, mas isso é algo que também não se encontra na lei original e podemos dizer que não há nessa nenhum respaldo para tanto.

Ao contrário, sempre caberia perguntar por que Sociologiae Filosofia vieram nomeadas tão explícita e claramente na lei, quando outros conhecimentos ou mesmo atividades, não se encontram em nenhum dispositivo sobre a educação básica ou o ensino médio.

Atentando ainda para essa preocupação mais legalista de "o que há" ou "o que não há" na legislação pertinente, podemos lembrar de outras disciplinas escolares como Física, Química e Biologia, ou até mesmo Geografia, que não constam explicitamente na lei (artigos 35 e 36, do ensino médio), mas que nem de longe são questionadas. Observe-se que o que poderia sugerir essas disciplinas aparece assim escrito na Lei (LDB 9394/96, art. 35, IV): "a compreensão dos fundamentos científico-tecnológicos dos processos produtivos, relacionando a teoria com a prática, no ensino de cada disciplina"; ou essa outra passagem, menos genérica (LDB 9394/96, Art. 36, I): "(0 currículo do ensino médio...) destacará a educação tecnológica básica, a compreensão do significado da ciência, das letras e das artes; o processo bistórico de transformação da sociedade e da cultura; a língua portuguesa como instrumento de comunicação, acesso ao conhecimento e exercício da cidadania"; e ainda no que se refere à Seção I - Da educação básica, reiterado pelo artigo 36, caput, temos: "O currículo do ensino nédio observará o disposto na Seção I deste Capítulo", e na Seção I, artigo 26, temos: "Os currículos do ensino fundamental e médio devem ter uma base nacional comum (...); $\$ 1^{\circ}$. os currículos a que se refere o caput devem abranger, obrigatoriamente, o estudo da língua portuguesa e da matemática, o conhecimento do mundo físico e natural e da realidade social e política, especialmente do Brasil". Noutros parágrafos, cita-se Artes ( $\$ 2^{\circ}$.) "como componente obrigatório", 
Educação Física $\left(\S 3^{\circ}\right.$.) "integrada à proposta da escola", "como componente curricular", nada dizendo se obrigatório ou não, ressalvando o seu "ajuste" às condições das escolas e turnos, e História do Brasil ( $§ 4^{\circ}$.), que deve levar em conta as contribuições de diferentes culturas e etnias que compõem o povo brasileiro.

Essa longa citação e comentários servem aqui para se perceber que nem todas as disciplinas constantes na prática e pela tradição dos currículos, aparecem citadas como "disciplinas obrigatórias" no corpo da lei. Pode-se entender que Física, Química, Biologia e Geografia sejam no ensino médio responsáveis por isso que na lei denomina-se "conbecimento do mundo físico e natural", mas o que se definiria como "conbecimento da realidade social e politica, especialmente do Brasil"? Apenas História, ou ainda Geografia? Ou podemos combinar esse dispositivo legal "conhecimento da realidade social e política, especialmente do Brasil" (LDB 9394/96, Art. 26, $\S 1^{\circ}$.) - com aquele outro que trata dos "conhecimentos de Filosofia Sociologia necessário ao o exercício da cidadania" (LDB 9394/96, art. 36, §1 ${ }^{\circ}$., III) e termos que Sociologia ( e Filosofia) passa a ser entendida como disciplina obrigatória.

\section{Parte II - Do Contexto Pedagógico}

Essa combinação sugerida acima permite que ao mesmo tempo que damos conta de contemplar a interpretação dada pelas DCNEM à LDB - em que pese reconhecer-lhe certa arbitrariedade e parcialidade -, avançamos para o entendimento de que a Sociologia possa ser assumida como disciplina escolar no nível médio como recorte das Ciências Sociais, tal como as demais disciplinas são "recortes" das Ciências Humanas, das Ciências Naturais, da Matemática, das Letras e Artes que são produzidas no mundo acadêmico. Assim "socializamos" com as demais disciplinas, "generosamente", a responsabilidade de formar para o "exercício da cidadania", mas reconhecemos o status científico da Sociologia e seu papel imprescindível no concerto curricular.

Podemos entender que haja um vínculo entre um currículo e uma formação do indivíduo e que esse vínculo está sobretudo fundado no caráter científico e cultural das disciplinas escolares. Essas disciplinas deveriam atender no ensino médio, tomado como etapa final da educação básica (art. 35), quatro finalidades principais: (I) "prosseguimento nos estudos"; (II) "preparação para a cidadania e o trabalho"; (III) "aprimoramento como pessoa humana"; (IV) "compreensão dos fundamentos científico-tecnológicos dos processos produtivos". Disso destacamos esse papel central das disciplinas escolares e, portanto do currículo, por representar uma possibilidade de o educando ter acesso a informações de caráter elaborado - rigoroso, sofisticado, racional, crítico - acerca da realidade em que vive - sociedade, economia, natureza, política, cultura -, dominando instrumentos de intervenção e contribuindo para as transformações necessárias. 
Parece que aqui entra uma disciplina escolar que seja a tradução de um campo científico específico - as Ciências Sociais. Não se pode entender que entre 15 e 18 anos, após 8, 9, 10 anos de escolaridade, o jovem ainda fique sujeito a aprender "noções" ou a exercitar a mente em debates circulares, aleatórios e arbitrários. Parece que nesta fase de sua vida a curiosidade vai ganhando certa necessidade de disciplinamento, o que demanda procedimentos mais rigorosos, que mobilizem razões históricas e argumentos racionalizantes acerca dos fenômenos - naturais ou culturais. Mesmo quando está em causa promover a tolerância ou combater os preconceitos, a par de um processo de persuasão que produza a adesão a valores, resta a necessidade de construir e demonstrar a "maior" racionalidade de tais valores diante dos costumes, das tradições e do senso comum. Tratase, mais uma vez recorrendo a Antonio Candido (1995), de "humanizar o homem". 0 acesso às ciências e às artes deve ser entendido dentro desse projeto: a escolha pelo homem de ser mais humano. Ora, há muito que as Ciências Sociais têm feito essa opção. Repugna ao cientista social submeter-se a um processo de "naturalização". Nem em Durkheim encontramos essa aceitação, em que pese os compromissos e contexto positivistas e funcionalistas de que participava o pensador.

Por outro lado, na medida em que a escola é um espaço de mediação entre 0 privado - representado pela família, sobretudo - e o público - representado pela sociedade (ARENDT, 1968) -, esta deve também favorecer, por meio do currículo, procedimentos e conhecimentos que façam essa transição. De um lado, o acesso a informações profissionais é uma das condições de existência do ensino médio; de outro, o acesso a informações sobre a política, a economia, o direito é fundamental para que o jovem se capacite para a continuidade nos estudos e para o exercício da cidadania, entendida estritamente como direito/dever de votar, ou amplamente como direito/dever de participar da própria organização de sua comunidade e País.

Numa sociedade em transição como a nossa, em que se acumularam formas tão variadas e intensas de exclusão social, em que a lentidão ou as "marches" e "démarches" são uma constante nas mudanças, o acesso ao conhecimento científico sobre esses processos constitui um imperativo político de primeira ordem.

Chegamos, então, à presença da Sociologia no nível médio. Aqui caberia transcrever as palavras deFlorestan Fernandes, em artigo publicado nos anos 50 e que tratava justamented'O ensino de Sociologia na escola secundária brasileira (CONGRESSO BRASILEIRO DE SOCIOLOGIA, 1954). Parece que, atualizando as palavras, reorientando as intenções, valem os mesmos objetivos e justificativas ainda hoje. Fernandes diz: "[...] a transmissão de conbecimentos sociológicos se liga à necessidade de ampliar a esfera dos ajustamentos e controles sociais conscientes, na presente fase de transição das sociedades ocidentais para novas técnicas de organização do comportamento bumano." 
Citando Manheim, ele acrescenta: "as implicações desse ponto de vista foram condensadas por Manheim sob a epigrafe 'do costume às ciência sociais' $e$ formuladas de uma maneira vigorosa, com as seguintes palavras: 'enquanto o costume e a tradição operam, a ciência da sociedade é desnecessária. A ciência da sociedade emerge quando e onde o funcionamento automático da sociedade deixa de proporcionar ajustamento. A análise consciente e a coordenação consciente dos processos sociais então se tornam necessárias".

Como se vê, as razões para que a Sociologia esteja presente no ensino médio no Brasil não só se mantêm como têm-se reforçado. As estruturas sociais estão ainda mais complexas, as relações de trabalho se atritam com as novas tecnologias de produção, 0 mundo está cada vez mais "desencantado", isto é, cada vez mais racionalizado, administrado, dominado pelo conhecimento científico e tecnológico. No campo político os avanços da democratização têm sido simultâneos aos avanços das tecnologias de comunicação e informação, tendendo a corromper-se esse regime político em novas formas de populismos e manipulações. No campo social, o predomínio do discurso econômico tem promovido uma "renaturalização" das relações, reforçando aqui o caráter ambíguo (e perverso) da racionalidade contemporânea.

0 ensino médio pode ser entendido como momento crucial de passagem na formação do indivíduo: para a escolha de uma profissão, para a progressão nos estudos, para o exercício da cidadania, o que quer que seja, entretanto, a presença ou ausência da Sociologia é desde já indício de escolhas, sobretudo no campo político.

A opção explícita feita pelas DCNEM pela interdisciplinaridade teve seus obstáculos quando passou das DCNEM para os PCNEM. Mas, mesmo no interior das DCNEM, encontramos certas contradições ou limites para a radicalidade de quem propunha uma alteração da perspectiva quanto às relações entre o conhecimento e o currículo. Se atentarmos bem, veremos que pelo menos duas disciplinas escolares não tiveram um questionamento profundo. As duas disciplinas que, mais do que as outras, são, atendendo ao espírito da Reforma, por excelência interdisciplinares. Aliás, por se tratar de linguagens, rigorosamente nunca poderiam sofrer a conformação de disciplinas escolares, mas, em que pese a verdade dessa reflexão, historicamente tornaram-se disciplinas centrais de qualquer organização curricular. Estamos falando de Língua (no nosso caso, Língua Portuguesa) e Matemática. São, desse ponto de vista, saberes em si mesmos instrumentais e presentes em todas as outras disciplinas. Apesar disso, reiteramos que não houve, em momento algum, uma proposta de que Língua Portuguesa e Matemática, após algumas séries em que devessem ser apresentadas e tratadas intensivamente, predominando no currículo, tornassem-se, com o passar do tempo, reconhecidas como parte de outras disciplinas, instrumentos de expressão ou de construção dos outros saberes. Pois, esses 
conhecimentos sustentam-se como disciplinas escolares na tradição e, por isso, estão garantidas. ${ }^{3}$

Além de Língua Portuguesa e Matemática, as DCNEM não criaram obstáculo a tantas outras disciplinas que, também pela tradição, viram-se legitimadas, com lugar definido no currículo. ${ }^{4}$ No entanto, "a corda arrebenta do lado mais fraco": Sociologia e Filosofia, nomeadas na LDB como conhecimentos cujo domínio é necessário para 0 exercício da cidadania, sofreram, da parte das DCNEM, um "veto" a serem tratadas como disciplinas e conteúdos obrigatórios. Seria difícil hoje, pela consulta aos documentos, entender essa exclusão tão peremptória em um texto que flerta o tempo todo com a flexibilização. Mas, encontramos, desde antes da aprovação das DCNEM, em esboços da Resolução que as regulamenta, um dispositivo legal em que se preconiza essa exclusão. ${ }^{5}$ Por outro lado, e na mesma minuta ainda, a atual área "Ciências Humanas e suas Tecnologias" era denominada "Sociedade e Cultura" que objetivava $a$ "construção de competências e habilidades que permitam ao educando traduzir, de forma crítica e criativa, o conhecimento das ciências sociais...". A mudança de nome, em tão curto período, (fins de 1997/meados de 1998) não conseguiu apagar totalmente certa inspiração nas Ciências Sociais. Muitas vezes já no Parecer 15/98 e Resolução 03/98 fala-se em "Ciências Humanas e Sociais" e em um escrutínio cuidadoso das "competências e habilidades", propostas para a área de Ciências Humanas e suas Tecnologias (Art.10, III), entre 9 itens (de $a$ a $i$ ), 1 apenas se refere especificamente à Geografia $(c), 2$ podem ser entendidos como compartilhados pela Sociologia e Filosofia ( $e$ e $g$ ), 1 compartilhado por Sociologia e História $(d)$, e 4 ou 5 especificamente definidos no campo das Ciências Sociais $(a, b, f, b$ e $i$ ). Embora muitos discursos (não só, mas especialmente nas Ciências Humanas) sejam generosos, ao assumir a presença tanto das Ciências Sociais quanto da Filosofia, como referências profundas e decisivas para suas revisões contemporâneas, essas disciplinas foram excluídas. Não houve tratamento isonômico entre as próprias humanidades e dessas em relação às demais disciplinas do currículo. Aqui, a oportunidade gerada pelas mudanças de alguns "consultores" e da Reforma das mãos da SEMTEC para as mãos da relatora indicada pelo CNE, revelou-se o mal-encontro entre aqueles que questionavam a predominância das Ciências Sociais na área - razão inclusive pela

\footnotetext{
${ }^{3}$ Se a Língua tem esse caráter instrumental, o mesmo não se pode dizer da Literatura, a não ser que seu ensino vise a apresentar modelos de redação...

${ }^{4}$ Observe-se que quando o governo assume uma postura liberal, acaba por reforçar práticas as mais conservadoras, e a tradição, e não a racionalidade, se impõe como regra. Num país como o Brasil, tão marcadamente desigual em todos os sentidos, a prática liberal não leva ao novo, ao divergente, ao criativo, pois tende mais para a segurança do conhecido, do costumeiro...

${ }^{5}$ Numa minuta, de 1997, da Resolução, lê-se: "Art. $1^{\circ} \S 4^{\circ}$ Os conhecimentos de Sociologia e Filosofia serão trabalhados interdisciplinarmente, objetivando o aprimoramento do educando como pessoa humana, sua formação ética, autonomia intelectual e pensamento crítico, numa perspectiva do pleno exercício da cidadania".
} 
mudança do nome-e a "visão desdisciplinarizadora" da conselheira relatora que resolveu excluir a Sociologia a Filosofia do currículo ao propor um "tratamento interdisciplinar e contextualizado" desses conhecimentos. Resta saber se as preconizadas "competências e habilidades" " "tecnologias" da área podem se sustentar nas duas disciplinas - História e Geografia - que, ao mesmo tempo que "bebem" naquelas outras disciplinas para se renovarem e se firmarem epistemológica e metodologicamente, quando não até discursivamente, as renegam como forma de garantir-se como saberes autônomos, territórios de objetos próprios, e ganhar maior espaço no currículo, sem ter de disputar com as disciplinas de outras áreas, diante das quais estão mais fragilizadas. ${ }^{6}$

No entanto, se observarmos bem a composição dos PCNEM, percebemos que sua inspiração é claramente disciplinar, apenas fazendo certa concessão à imposição que as DCNEM determinaram de se buscar a interdisciplinaridade. Mas ainda assim, há um PCNEM de sociologia e numa passagem bastante explícita da "Apresentação" da Área de Ciências Humanas e suas Tecnologias, temos:

Chamamos a atenção para o fato de que, neste documento, ao desenvolvermos textos específicos voltados para os conhecimentos de História, Geografia, Sociologia e Filosofia, babitualmente, formalizadas em disciplinas escolares (sic), incluimos diversas alusões - explícitas ou não - a outros conbecimentos das Ciências Humanas que consideramos fundamentais para o Ensino Médio.

Observe-se que a expectativa do documento é que tais "conhecimentos" sejam formalizados em "disciplinas escolares", dentre as quais encontra-se a Sociologia. Mas se ainda não ficou tão claro, na sequiência do documento, apresenta-se um contraste para isso:

"(sobre outros conhecimentos das Ciências Humanas que se considera fundamentais para o Ensino Médio) trata-se de referências a conhecimentos de Antropologia, Política, Direito, economia e Psicologia. Tais indicações não visam a propor à escola que explicite denominação e carga horária para esses conteúdos na forma de disciplinas".

0 que se entende daí éque as primeiras quatro formas de "conhecimentos" devem ser "formalizadas em disciplinas escolares" e as cinco outras não necessariamente. Se lembrarmos que os PCNEM da Área de Ciências Humanas, conforme diz a "Apresentação", já estavam "levando em conta as disposições do Parecer no. 15, que integra a Resolução no. 3/98", isto é, as DECNEM, parece contraditório que Sociologia não seja

\footnotetext{
${ }^{6}$ História e Geografia mantêm sempre à vista o fantasma dos Estudos Sociais, a fim de impedir tentativas interdisciplinares que as reúnam novamente, mas também que as obrigue a dividir espaço com Sociologia e Filosofia.
} 
tomada pelas DCNEM como disciplina e que os PCNEM o façam. Como os PCNEM vinham sendo elaborados desde 1996 - contemporaneamente à tramitação da LDB no Congresso Nacional -, conforme diz a mesma "Apresentação", entende-se que os PCNEM "conservem mais" o espírito original que levou o legislador a grafar explicitamente na LDB 9394/96, que ao fim do ensino médio o educando demonstre "domínio de conhecimentos de Filosofia e Sociologia necessários ao exercício da cidadania", do que as DCNEM, que são de 1998 e alteraram essa disposição, pois estas sofreram os reveses de mudanças das equipes de elaboração e, conseqüentemente, de orientação, afastando-se claramente - inclusive no tempo - do "espírito da lei" (BRASIL, 1996).

Por fim, caberia perguntar como garantir que os "conhecimentos de Filosofia e Sociologia necessários ao exercício da cidadania" sejam tratados efetivamente pelas demais disciplinas escolares, ou seja, como dizem as DCNEM, com "tratamento interdisciplinar e contextualizado"? Aqui valeria a pena discutir alguns aspectos da "realidade" das escolas a fim de demonstrar que essa interpretação da lei acaba por levar ao descumprimento efetivo da lei, ou seja, que não fica assegurado que "ao fim do ensino médio o educando demonstre domínio de conhecimentos de Filosofia e Sociologia necessários ao exercício da cidadania" (LDB 9394/96, art. 36, § 1, III). Primeiramente, quais disciplinas incorporariam aos seus conteúdos os "conhecimentos" de Filosofia e Sociologia? Segundo, que domínio dos conteúdos de Filosofia e Sociologia têm os professores de outras disciplinas - sabendo das deficiências de formação específica que a maioria dos professores têm... - e em que medida isso ésuficiente para que eles transmitam os "necessários" conforme determina a lei? Que domínio de "metodologias de ensino interdisiplinares" têm os professores para que possam dar o "tratamento interdisiplinar" que a lei derivada determina para que se contemple o estabelecido na lei original? Assim como as demais disciplinas, cada vez menos se entende que esses "conhecimentos" sejam apenas informações, valorizando-se em especial as metodologias de pesquisa e, na linguagem das próprias DCNEM, as "tecnologias" da Sociologia, então, que domínio têm os professores de outras disciplinas dessas metodologias e tecnologias para garantir que elas recebam tratamento interdisciplinar e contextualizado e contribuam para a formação plena do educando?

A partir do exposto acima, propomos que seja alterada a Resolução 03/98, no seu $\operatorname{artigo~} 1^{\circ}, \S 2^{\circ}$, com a supressão da alíneab) e inclusão do $\S 3^{\circ}$ com a seguinte redação: "As propostas pedagógicas das escolas deverão assegurar tratamento de componente disciplinar obrigatório à Sociologia".

É importante esclarecer que não haverá impacto financeiro nos sistemas de ensino, dado que poderá haver remanejamento interno aos currículos escolares, uma vez que a saída dessa disciplina foi acompanhada pelo aumento de aulas de outras disciplinas que, assim com a nova redação da lei, voltam ao seu status quo ante, abrindo espaço para a 
reintrodução da Sociologia. Ademais, mais da metade das unidades da federação já contemplam a Sociologia como disciplina obrigatória nos currículos escolares médios. Há também que se ressaltar que inúmeras universidades já incluíram o conhecimentos de Sociologia em seus processos seletivos. Aqui não avançamos para estipular o número de aulas por série nem o número de séries com a disciplina, mas entendemos que 0 mínimo razoável seria pelo menos 2 (duas) aulas em 1 (uma) série do nível médio. Acima disso é da autonomia da escola estabelecer.

\section{ResoluÇão CEN/CEB/2005}

Estabelece Diretrizes para a disciplina Sociologia no ensino médio, e altera a Resolução CNE/CEB 03/98, dando nova redação ao artigo 10, $§ 2^{\circ}$, acrescentando o $\$ 3^{\circ}$ ,como segue:

Artigo $1^{\circ}$ : É acrescentado o $§ 3^{\circ}$ ao artigo 10 da Resolução CEN/CEB 03/98, com a seguinte redação:

Art. 10.

$\S 3^{\circ}$ As propostas pedagógicas das escolas deverão assegurar tratamento de componente disciplinar obrigatório para a Sociologia".

Artigo 2: Esta lei entra em vigor na data de sua publicação;

Artigo 3: Revoga-se a alínea b) do $§ 2^{\circ}$ do Artigo $1^{\circ}$ da Resolução CEN/CEB 03/98.

\section{REFERENCIAS}

ARENDT, Hannah. Entre o Passado e o Futuro. São Paulo: Perspectiva, 1968.

BRASIL. Lei no 9.394, de 20 de dezembro de 1996. Lei de Diretrizes e Bases. Estabelece as diretrizes e bases da educação nacional. Brasília: Senado Federal, 1996.

CÂNDIDO, Antonio. Vários Escritos, São Paulo: Duas Cidades, 1995.

CONGRESSO BRASILEIRO DE SOCIOLOGIA, 1., 1954, São Paulo. Atas... São Paulo, 1954. 